\title{
A metafunção composicional em charges de futebol: um estudo do espaço visual à luz da Gramática do Design Visual
}

\author{
Gustavo Ewerson da Rocha Balbino \\ Universidade Estadual do Ceará \\ Antônia Dilamar Araújo \\ Universidade Estadual do Ceará
}

\begin{abstract}
Resumo
Atualmente, na sociedade moderna e globalizada, com o advento da tecnologia, a produção de textos visuais cresce desenfreadamente. A charge, como gênero multimodal, combina a modalidade escrita e visual para criar o ato comunicativo multimodal. Tendo em vista a complexidade desse gênero, este artigo tem como objetivo analisar a manifestação do significado composicional em charges de futebol. Servimo-nos da Teoria da Multimodalidade que surge como campo de estudo preocupado em investigar como os modos semióticos são produzidos, distribuídos e interpretados. Para tal estudo, nos baseamos na Gramática do Design Visual de Kress e van Leeuwen (2006) para a análise do texto visual. Para nossa análise, selecionamos duas charges com a temática do futebol para um estudo descritivo e interpretativo. Esse estudo aponta para o entendimento de que as charges são representações da realidade do futebol socialmente construídas e que suas publicações na mídia são realizações materiais desse discurso.
\end{abstract}

Palavras-chave: multimodalidade, metafunção composicional, charge.

\begin{abstract}
In the modern and globalized society, with the rise of technology, the production of visual texts has grown wildly. The cartoon, as a multimodal genre, combines written and visual modalities to create a multimodal communicative act. Considering the complexity of this genre, this article aims to analyze the manifestation of compositional meaning in cartoons about soccer. We have based our work on the Multimodality Theory that emerges as a field of research concerned with investigating how semiotic modes are produced, distributed, and interpreted. For this study, we focus on the Grammar of Visual Design of Kress and van Leeuwen (2006) for visual text analysis. For our analysis, we selected two cartoons with a soccer theme for a descriptive and interpretive study. This study points to an understanding that cartoons are socially constructed representations about soccer reality, and their publications in media are a material performance of this discourse.
\end{abstract}

Keywords: multimodality, meaning of composition, cartoon.

\section{INTRODUÇÃO}

Durante muito tempo, os estudos semióticos se preocuparam apenas com a linguagem verbal escrita. No entanto, com a diversidade dos gêneros textuais/discursivos, não há como fechar os olhos para as imagens, o layout, o design e as tipografias empregadas na 
construção dos textos modernos. O advento da tecnologia possibilitou a manipulação dos diversos modos semióticos em suas instâncias comunicativas, de forma que a sociedade moderna tem se tornado cada vez mais multimodal. Curiosamente, a charge é um gênero textual/discursivo que tem acompanhado essa transformação tecnológica. Antigamente, as charges eram publicadas apenas em jornais e revistas impressas, mas hoje elas são facilmente distribuídas na web por meio de blogs e das redes sociais. Apesar da mudança na sua produção e distribuição, a charge ainda mantém suas caraterísticas básicas, como abordar assuntos cotidianos, utilizar figuras de linguagem (ironia e metáfora), provocar riso e reflexão crítica. Contudo, a modalidade visual, tão importante quanto os aspectos elencados anteriormente, é negligenciada pela tradição da semiótica estruturalista.

Apesar da combinação do modo escrito e visual na composição da charge, muitas vezes, a modalidade visual é analisada sem uma metalinguagem específica. Comentários e impressões superficiais acerca da modalidade visual não correspondem com a postura científica (KRESS e VAN LEEUWEN, 2001). Por isso, ao considerar a charge como texto multimodal, é preciso notá-la como declaração visual com léxico próprio e dotada de uma gramática. Assim como a escrita, a comunicação visual tende a ser afetada pela convenção cultural do Ocidente que adota a escrita da esquerda para direita, de cima para baixo. Evidentemente, diferentes valores e significados podem estar ligados a essas orientações no espaço visual (KRESS e VAN LEEUWEN, 2006). Portanto, esses valores exercem alguma influência na forma como a modalidade visual será construída culturalmente. No que concerne à complexidade do gênero charge, desperta-nos o seguinte questionamento: como são construídos os significados no espaço visual da charge?

Tomando por base essa questão, este trabalho se propõe a analisar a constituição do significado composicional no espaço visual da charge. Para alcançar esse objetivo, utilizamos como aporte teórico-metodológico a Teoria da Multimodalidade e a Gramática do Design Visual (Doravante GDV), que têm se preocupado - não apenas com a língua escrita mas em investigar como os significados são construídos, distribuídos, recebidos, interpretados através de várias representações e modos comunicativos (JEWITT, 2014). A fim de descrever o modo visual, Kress e van Leeuwen (2006) propuseram a GDV. Na Semiótica Social, essa proposta assume um importante papel científico ao estudar "a maneira como os elementos representados (pessoas, lugares e coisas) combinam-se em declarações visuais de maior ou menor complexidade e extensão" (KRESS e VAN LEEUWEN, 2006, p. 1) ${ }^{1}$.

\footnotetext{
${ }^{1}$ Nossa tradução de: " the way which depicted elements - people, places and things - combine in visual 'statements' of greater or lesser complexity and extension"
} 
Para obtermos uma visualização panorâmica desse campo de estudo, fizemos um breve levantamento de pesquisas sobre charge no Brasil sob a ótica da Teoria da Multimodalidade. Para realizar o levantamento, foram analisadas 13 publicações científicas em língua portuguesa. Desse universo, identificamos 9 artigos publicados em periódicos eletrônicos e 4 dissertações de programas de pós-graduação de universidades brasileiras. Para coletar essas publicações, utilizamos a ferramenta de busca do site www.google.com para identificar os trabalhos com título que contivessem as palavras "análise multimodal", "charge", "multimodalidade" e "gramática do design visual". Durante a busca, fizemos uma leitura dos resumos, texto completo e palavras-chave para selecionar aqueles que realizaram análise multimodal de charges. Dos trabalhos analisados, apenas Knoll (2015) e Cavalcanti (2008) utilizaram efetivamente a GDV para interpretar o gênero charge. Os autores destacaram a importância do modo semiótico imagético ao utilizar a GDV como instrumento de análise. Por outro lado, os demais trabalhos, mesmo considerando a charge como gênero multimodal, não usaram uma metalinguagem específica. Os estudos sobre charge, cujas análises são realizadas por meio de uma gramática no Brasil são relativamente novos, porque a Teoria da Multimodalidade ainda está se consolidando no cenário internacional. Isso nos serve de justificativa para a realização da pesquisa relatada neste artigo, pois nos debruçamos sobre uma questão pertinente e pouco explorada. Além disso, a habilidade para compreender os padrões de tais significados visuais é muito importante no desenvolvimento do Letramento Visual de cada cidadão do mundo moderno e globalizado.

Este trabalho está dividido em três partes. Primeiro, apresentamos a fundamentação teórica que trata da Multimodalidade e da GDV. Em seguida, explicamos a nossa metodologia de pesquisa adotada. Por último, analisamos o valor de informação, a saliência e a estruturação da metafunção composicional de duas charges de futebol publicadas no site www.lance.com.br, durante o ano de 2015.

Na próxima seção, discutiremos sobre Multimodalidade.

\section{MULTIMODALIDADE}

Até pouco tempo, no mundo ocidental, muitos teóricos acreditavam no mito da 'monomodalidade'. Cada campo de estudo criava uma metalinguagem para falar sobre seu objeto de estudo. Diversos campos de estudos - tais como a História da Arte, a Linguística, a Teoria Musical - tinham seus próprios métodos, pressupostos e vocabulário técnico. Atualmente, essa dominância está começando a mudar, porque tanto mudaram os textos 
quanto a visão científica (KRESS, 2000). Na década de 90, os pesquisadores Kress e van Leeuwen (2006) começaram a realizar diversos estudos semióticos com outros modos semióticos. Em 1996, preocupados com a modalidade visual, eles publicaram a Gramática do Design Visual, com o objetivo de analisar estruturas visuais e outros códigos semióticos nãoverbais de textos por meio de normas e regras. Com base nos princípios da Semiótica Social e da GDV, vários trabalhos vêm sendo publicados relacionados à música, à tipografia, relação texto e imagem, à imagem em movimento e tantos outros.

Atualmente, Kress e van Leeuwen tentam consolidar o campo de pesquisa da multimodalidade internacionalmente, mas, segundo Kress (2000), ainda há uma grande hegemonia da língua verbal nos estudos semióticos. É preciso repensar constantemente a linguagem como fenômeno multimodal, ou seja, observar o texto para além da linguagem verbal em suas instâncias contextuais de uso. Para Kress (2000, p. 182), “o efeito desta revolução foi deslocar a linguagem escrita da centralidade que ela ocupou, ou que foi atribuída a ela, na comunicação social"2. Para Kress e van Leeuwen (2006), até o texto escrito é multimodal, porque a tipografia (fonte com serifa, fonte sem serifa, em negrito, itálico, tracejada) é um recurso significativo e, consequentemente, multimodal. O significado não é uma construção puramente linguística, mas uma complexa interrelação entre os recursos linguísticos, visuais, gestuais, gráficos e musicais que se interligam no ato comunicativo (KRESS, 2000).

A Teoria da Multimodalidade surge para descrever os modos semióticos que se referem aos meios articulados de representação e comunicação (Ibid., 2000). As imagens, os gestos, o sistema de olhar, a postura e os sons são modos semióticos que podem ser usados simultaneamente para construir um significado. Ao proferir uma palestra, por exemplo, geralmente o palestrante utiliza ao mesmo tempo a linguagem verbal falada, os gestos e a postura. Tudo isso pode ser visto como sistema de fazer significados interdependente e simultâneo. Kress e van Leeuwen (2006) entendem que cada um desses modos semióticos tem seu potencial de significação e interrelação com outros modos semióticos (KRESS, 2000). Dessa forma, a multimodalidade pode ser usada para construir um inventário de recursos semióticos que disponibiliza modos para pessoas em lugares e momentos específicos (JEWITT, 2014).

Em relação aos fundamentos teóricos, esse campo de estudo, segundo Jewitt (2014), está articulado em quatro pontos fundamentais. Em primeiro lugar, os significados são

\footnotetext{
${ }^{2}$ Nossa tradução de: "the effect of this revolution has been to dislodge written language from the centrality which it has held, or which has been ascribed to it, in public communication."
} 
construídos, distribuídos, recebidos e interpretados através de várias representações e modos comunicativos (não apenas na linguagem verbal). Em segundo lugar, cada modo nesse texto multimodal desempenha uma função diferente e complementar, e embora haja a dominância de um ou de outro modo, eles nunca aparecem isolados. Em terceiro lugar, de posse de um conjunto de recursos semióticos disponíveis, as pessoas constroem textos segundo seu interesse. Para a Semiótica Social, os signos são motivados, ao invés de arbitrários, conforme defendia Saussure (2004). Por último, os textos multimodais são sociais e culturalmente estabelecidos.

Quanto às ferramentas tecnológicas, elas são também decisivas nas funções semióticas dos textos multimodais. Antes os textos eram prioritariamente impressos, mas hoje eles são transmitidos em tela. Além disso, o desenvolvimento da web favoreceu a criação de textos inéditos, como infográficos interativos, por exemplo. Segundo Almeida (2011), isso apresenta um desafio para os professores, porque geralmente a escola ainda está limitada ao ensino da língua escrita. Mas a multimodalidade aponta para a necessidade de novas práticas pedagógicas que contemplem o letramento múltiplo além da linguagem escrita, ou seja, os multiletramentos (KRESS e VAN LEEUWEN, 2006). A pedagogia dos multiletramentos tende a promover eventos de letramento que buscam desenvolver a habilidade de entender e produzir textos multimodais já concretizados em práticas sociais.

Quando se fala em textos visuais, é exigido um amplo conceito de leitura. Diferentemente da leitura de texto em língua escrita, que é linear e sequencial, a leitura das imagens é simultânea. Há, portanto, muitos caminhos de leituras em um texto multimodal. Isso depende da forma como os significados foram construídos pelo produtor da imagem. Kress e van Leeuwen (2006) observaram que esses significados são comuns a todas as imagens e poderiam ser descritos por metafunções. Então, a GDV surge como uma importante base para análise dos textos visuais.

\section{GRAMÁTICA DO DESIGN VISUAL}

A Linguística Sistêmico-Funcional (LSF) criada por Halliday (1985) inspirou a GDV na tentativa de explicar o uso da linguagem como forma de interação. Nos termos de Austin (1962), a interação é um 'ato de fala', porque, ao proferir um texto, o falante exige uma reação de seu interlocutor. Na interação, os interlocutores utilizam um conjunto de recursos semióticos que são articulados através de sistemas semióticos. Como a língua é instrumento de interação social, a motivação para a materialização do discurso está no 
contexto. Segundo Cunha, Costa e Cezário (2015, p. 21), “a estrutura gramatical depende do uso que se faz da língua, ou seja, a estrutura é motivada pela situação comunicativa". Portanto, "as formas gramaticais são recursos para codificar interpretações de experiências e formas de interação social." (KRESS e VAN LEEUWEN, 2006, p. 1) . $^{3}$

Influenciados por essa abordagem funcionalista, Kress e van Leeuwen (2006) propõem uma gramática da modalidade visual como "forma de estender a compreensão e leitura das imagens sistematizando seu estudo, já que ambos os autores encontram pontos consoantes entre o texto visual e o texto escrito" (ALMEIDA, 2011, p. 46). À primeira vista, a GDV pode estar relacionada ao discurso normativo ou à ideia de correção, mas, longe da perspectiva prescritiva, Kress e van Leeuwen (2006) tentam identificar padrões significativos que as imagens manifestam nas diversas culturas ocidentais. O objetivo da gramática é sistematizar as principais estruturas composicionais, representacionais e interativas que têm se tornado convenções ao longo da história da humanidade e analisar como elas são usadas pelos produtores de imagem contemporâneos para produzir sentido (KRESS e VAN LEEUWEN, 2006).

Segundo Kress e van Leeuwen (2006), as imagens apresentam padrões de sintaxe visual que são identificados por meio das metafunções representacional, interativa e composicional. Primeiramente, a metafunção representacional é construída por estruturas narrativas e conceituais. Esse significado nos diz que eventos narrativos, ações e processos enunciativos estão acontecendo na imagem. Além disso, é possível descobrir quais são os processos de atribuição conceitual dos elementos ali retratados. Por sua vez, a metafunção interativa diz respeito à forma como se estabelece a relação do texto com o leitor. Nessa dimensão interativa, pressupõe-se que o olhar dos participantes retratados, por exemplo, estabelece uma relação de contato com o observador. Por último, a metafunção composicional desempenha um importante papel na organização do texto visual. Detalhamos a metafunção composicional na subseção a seguir.

\section{Metafunção composicional}

Diferentemente do texto escrito que apresenta uma ordenação linear de leitura (da esquerda para direita, de cima para baixo), segundo Bull e Anstey (2010), os textos visuais transmitem significados por meio de uma combinação de elementos que se baseiam em vários

\footnotetext{
${ }^{3}$ Tradução nossa de: "grammatical forms as resources for encoding interpretations of experience and forms of social (inter)action."
} 
sistemas semióticos. Nesses textos, há muitos caminhos de leituras disponíveis e muitas decisões são tomadas por meios dos significados composicionais. Por significado composicional, Kress e van Leeuwen (2006, p. 176) explicam que é a "a composição do todo, a maneira na qual os elementos representacionais e interativos são construídos para relacionarem-se entre si, a maneira que eles se integram dentro do um todo significativo"4. Essa metafunção está relacionada à coesão do texto visual, ou seja, à forma como o produtor organiza o significado no espaço do texto visual. A metafunção composicional está dividida em três sistemas interdependentes: valor de informação, saliência e estruturação ${ }^{5}$ (Figura 1).

Figura 1: Metafunção composicional

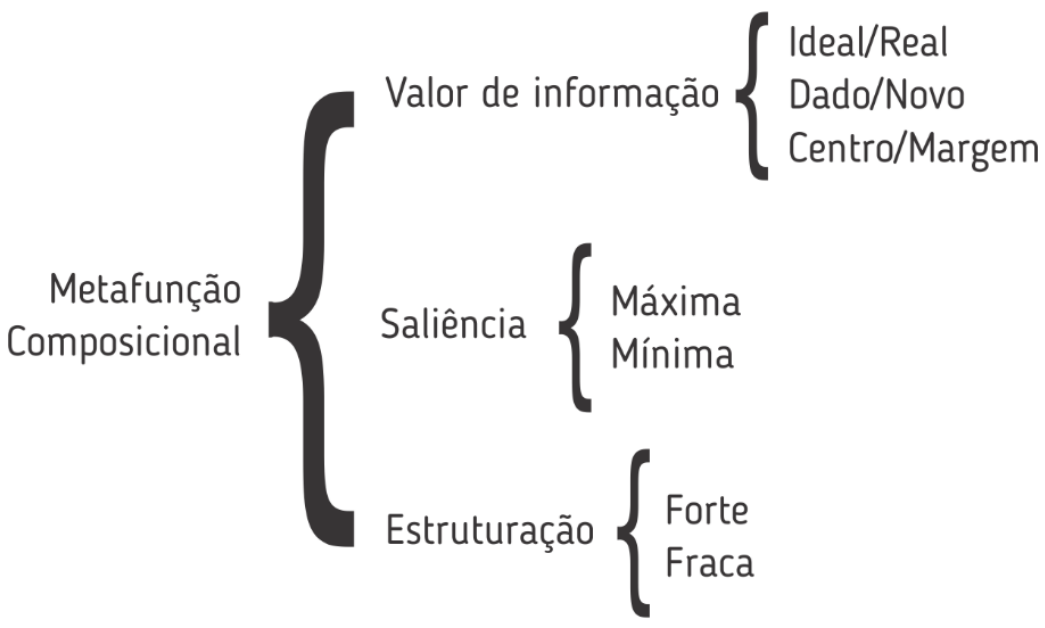

Fonte: Kress e van Leeuwen (2006).

$O$ valor de informação pode ser identificado pela localização dos elementos (pessoas, objetos, balões, textos etc) relacionada às três principais regiões da imagem: esquerda/direita, superior/inferior, centro/margem.

$\mathrm{Na}$ linha horizontal, se estabelece a relação entre dado e novo. Geralmente localizado no lado esquerdo da imagem, o significado é dado, quando é familiar ao leitor. Empregada no lado direito, a informação nova significa o desconhecido ou chama a atenção do leitor.

$\mathrm{Na}$ linha vertical, pode ocorrer a relação ideal e real. A parte superior da imagem aponta para "o que deveria ser" (um desejo, um sonho, uma ideia, um objetivo). O significado ideal pode ser representado como "a essência ideal ou geral da informação, portanto, também

\footnotetext{
${ }^{4}$ Nossa tradução de: "the composition of the whole, the way in which the representational and interactive elements are made to relate to each other, the way they are integrated into a meaningful whole".

${ }^{5}$ Não há um consenso entre os pesquisadores brasileiros da tradução do termo "framing" para o português. Optamos por usar o termo "estruturação".
} 
como sua parte ostensivamente mais saliente" (KRESS e VAN LEEUWEN, 2006, p. 186) Por outro lado, a parte inferior é oposta ao ideal, pois indica “o que está acontecendo" ou "o que é" na realidade. Essa região é usada para descrever um produto num cartaz publicitário, por exemplo.

A terceira relação de valor de informação se estabelece entre o centro e as margens da imagem. No centro, encontramos o núcleo da informação da imagem que rege os demais elementos marginais. Portanto, o centro é o pivô da construção imagética e os elementos secundários se localizam ao seu redor (veja Figura 2).

Figura 2: Bloco informacional de uma composição multimodal

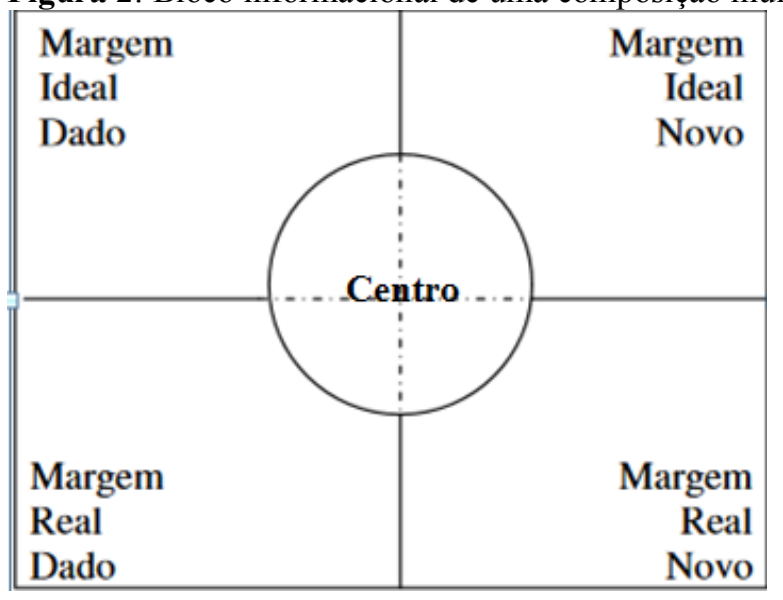

Fonte: Kress e van Leeuwen (2006).

A saliência diz respeito ao recurso de integração visual. A composição visual é organizada por elementos "para atrair atenção do leitor para diferentes graus, realizados pelos fatores de localização em primeiro plano ou plano de fundo, tamanho relativo, contrastes em valores tonais (cor), diferenças de nitidez etc.” (KRESS e VAN LEEUWEN, 2006, p. 177)7 . Independente do posicionamento dos elementos (valor de informação), a saliência pode atribuir um maior ou menor destaque em determinamos elementos para a construção de uma hierarquia de informação.

A estruturação está relacionada à conexão entre os elementos significativos de texto visual. À medida que o autor optar em separar por linhas divisórias, menos conectados estarão os participantes da imagem e maior será a estruturação. Segundo Kress e van Leeuwen (2006), a estruturação se refere "à presença ou ausência de dispositivos de conexão

\footnotetext{
${ }^{6}$ Nossa tradução de: "idealized or generalized essence of the information, hence also as its, ostensibly, most salient part."

${ }^{7}$ Nossa tradução de: "to attract the viewer's attention to different degrees, as realized by such factors as placement in the foreground or background, relative size, contrasts in tonal value (or colour), differences in sharpness, etc."
} 
(realizados por elementos que criam linhas divisórias ou por linhas de quadros reais), desconecta ou conecta elementos da imagem" (KRESS e VAN LEEUWEN, 2006, p. 177) ${ }^{8}$. Portanto, se há conexão entre os elementos significativos na imagem, ausência de linhas divisórias, a estruturação é fraca e pode representar um sentido de identidade de grupo. Em contrapartida, se houver desconexão entre os elementos, presença de linhas divisórias, a estruturação é forte e pode representar individualidade.

\section{METODOLOGIA}

Esta pesquisa adota o método indutivo de investigação, pois analisamos dados particulares, suficientemente constatados, para em seguida inferirmos uma verdade geral ou universal, não contida das partes examinadas (LAKATOS e MARCONI, 1992). Quanto à abordagem dos dados, trata-se de uma pesquisa qualitativa e interpretativa, uma vez que trabalhamos com a interpretação de textos visuais. Em relação aos objetivos, a pesquisa é descritiva, porque identifica os fatores que determinam ou que contribuem para a ocorrência dos fenômenos (GIL, 2002).

O corpus do nosso artigo foi selecionado com base em dois critérios: charge com temática de futebol e publicada em blog. Desse modo, escolhemos duas charges publicadas no ano de 2015 no site www.lance.com.br. Os procedimentos de análise envolvem a descrição do texto visual de acordo com a metafunção composicional da GDV (valor de informação, saliência e estruturação) para responder ao questionamento inicial: como são construídos os significados no espaço visual da charge? A fim de atribuir um significado mais amplo às respostas da questão de pesquisa, levamos em conta a temática e o contexto no qual as charges foram inseridas.

\section{ANÁLISE DO CORPUS}

Começamos nossa análise com a Figura 3. A charge faz referência à disputa do Campeonato Brasileiro 2015 (série A), quando o time do Vasco estava nas últimas posições da tabela e lutava para não cair para a segunda divisão. $O$ chargista produziu o texto visual segundo alguns padrões de experiências que fazem referência aos termos típicos do futebol, como: cair, subir, fundo do poço, topo da tabela etc. Logo, essas expressões do discurso

\footnotetext{
${ }^{8}$ Nossa traduação de: "The presence or absence of framing devices (realized by elements which create dividing lines, or by actual frame lines) disconnects or connects elements of the image"
} 
verbal também se organizam em três funções comunicativas visuais: valor de informação, saliência e estruturação (veja Figura 3).

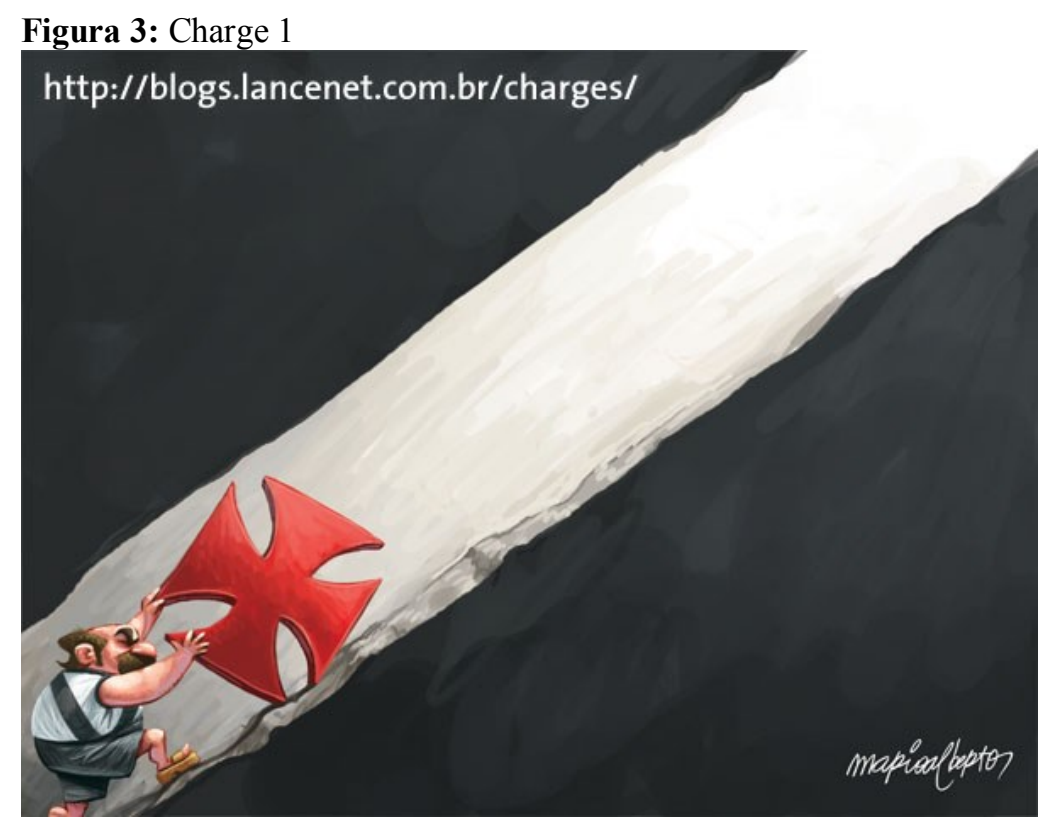

Imagem extraída do site: www.lancenet.com.br/charges

O valor de informação é estabelecido tanto pela linha horizontal quanto pela vertical. Podemos traçar um vetor na diagonal da esquerda/inferior para direita/superior, conforme a ação do participante. Localizado no lado esquerdo, o mascote do Vasco luta para subir com a cruz de Malta (escudo que se localiza na camisa oficial do Vasco no lado superior direito). Metaforicamente falando, a informação dada, que estava à disposição de todos, é a luta do time para escapar do rebaixamento. Em contrapartida, informação nova e ideal é a posição almejada na parte superior à direita. Desse modo, o topo da imagem simboliza as primeiras colocações na tabela do campeonato.

Em relação à saliência, as cores merecem um destaque na Figura 3, porque, apesar da predominância da baixa saturação na charge, o vermelho da cruz de Malta se destaca. A ênfase no elemento vermelho não é por acaso, porque, como vimos no valor de informação, a leitura do texto visual tende a começar na região inferior à esquerda. Dessa forma, a cruz de Malta é constituída com máxima saliência em relação às tonalidades de cores. Outro fator interessante das cores nessa charge é que elas assinalam para a coesão do espaço visual. As cores preto e branco preenchem o plano de fundo da charge e fazem referência ao formato da camisa e ao escudo do time do Vasco da Gama.

Por fim, há linhas divisórias delimitadas pelas cores preto e branco e percebe-se que há desconexão entre o mascote do Vasco e o plano de fundo. Essa desconexão nos leva a 
concluir com base nos conceitos da GDV que, a estruturação é forte, uma vez que seus elementos não estão interligados em um fluxo contínuo por meio de cores e formas semelhantes. Portanto, a presença dessa faixa branca na diagonal isola o mascote do Vasco em relação ao plano de fundo preto. Essa desconexão representa a longa distância do time carioca para sair da zona de rebaixamento.

A segunda charge, Figura 4, faz referência ao duelo paulista entre São Paulo e Santos válido pelo Campeonato Brasileiro de 2015. É retratada na charge a expectativa do tricolor paulista ao enfrentar a equipe santista (veja Figura 4).

Figura 4: Charge 2

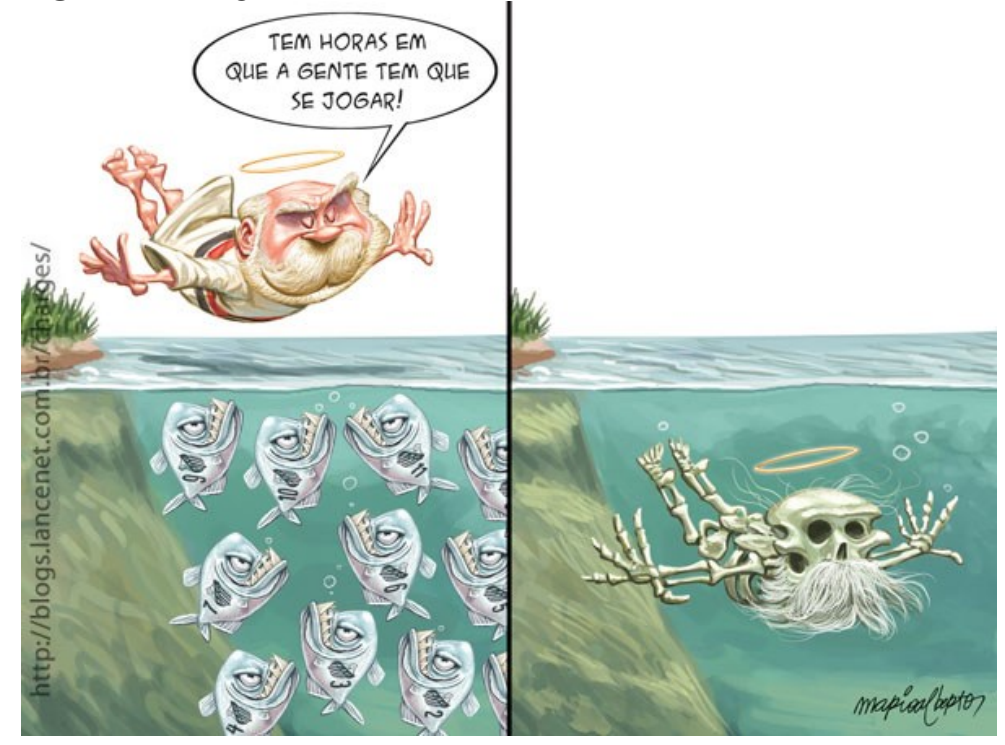

Imagem extraída do site: www.lancenet.com.br/charges

Quanto ao valor de informação, a imagem se polariza em dois blocos informativos: dado/novo e ideal/real. Na esquerda, a informação dada é uma expectativa de triunfo tricolor diante da equipe santista. $\mathrm{O}$ enunciado "tem horas em que a gente tem que se jogar" é ambíguo, pois o verbo "jogar" relaciona-se com o ato de "jogar futebol”, mas também faz referência ao sentido metafórico de "arriscar-se". Entretanto, na direita, o mascote do São Paulo não obteve êxito, pois foi atacado pelos peixes (os jogadores do Santos) que o aguardavam debaixo d'água no quadro da esquerda. A informação nova, portanto, foi o desfecho desfavorável para o mascote do São Paulo. Já as regiões superiores e inferiores estão relacionadas ao movimento do mascote do São Paulo em direção à agua. No quadro da esquerda, o mascote é apresentado na região superior como algo idealizado sobre as águas. Em contrapartida, o quadro da direita, na posição inferior, retrata o que aconteceu quando o São Paulo caiu na água, ou seja, retrata a derrota do São Paulo para a equipe santista. 
Já a saliência, nessa charge, é bem sutil em relação ao vermelho da cruz de Malta da charge anterior. Não há elementos em destaques em primeiro plano, ou elementos mais nítidos que outros, ou diferença de saturações de cores. Chama atenção apenas o tamanho do balão da fala do mascote e a grande quantidade de peixes (representando a equipe santista) debaixo d'água no primeiro quadrinho.

Por fim, completando os significados composicionais, diferentemente da primeira charge, o autor se valeu do espaço visual para estabelecer um recurso semiótico típico de História em Quadrinhos (HQs). Representando dois momentos distintos, o chargista organizou o texto visual em dois quadros sequenciais: o antes (à esquerda) quando o São Paulo se arrisca ao se lançar nas águas e o depois (à direita) que representa o resultado do jogo e o São Paulo derrotado pelo time santista. Portanto, a linha divisória vertical entre os dois quadros narrativos estabelece uma estruturação forte, pois delimita temporalmente dois acontecimentos.

A seguir, no Quadro 1, apresentamos a síntese de nossa análise:

Quadro 1: Síntese de análise

\begin{tabular}{|c|c|c|c|}
\hline \multirow{2}{*}{\multicolumn{2}{|c|}{$\begin{array}{l}\text { METAFUNÇÃO } \\
\text { COMPOSICIONAL }\end{array}$}} & \multicolumn{2}{|c|}{ CHARGES } \\
\hline & & 1 & 2 \\
\hline \multirow{6}{*}{$\begin{array}{l}\text { Valor de } \\
\text { informação }\end{array}$} & Ideal & $\begin{array}{l}\text { Saída do poço (saída } \\
\text { da zona de } \\
\text { rebaixamento). }\end{array}$ & $\begin{array}{l}\text { Idealização do mascote } \\
\text { em cima d'água (antes do } \\
\text { confronto). }\end{array}$ \\
\hline & Real & $\begin{array}{l}\text { Fundo do poço } \\
\text { (zona de } \\
\text { rebaixamento). }\end{array}$ & $\begin{array}{l}\text { Os peixes (equipe do } \\
\text { Santos) aguardando o } \\
\text { mascote do São Paulo } \\
\text { cair na água antes do } \\
\text { confronto. O mascote do } \\
\text { São Paulo devorado } \\
\text { debaixo d'água depois do } \\
\text { confronto. }\end{array}$ \\
\hline & Dado & $\begin{array}{l}\text { O mascote está } \\
\text { lutando para sair do } \\
\text { fundo do poço (Vasco } \\
\text { tentando sair da zona } \\
\text { de rebaixamento). }\end{array}$ & $\begin{array}{l}\text { O mascote do São Paulo } \\
\text { encontra-se intacto antes } \\
\text { de se jogar na água. }\end{array}$ \\
\hline & Novo & $\begin{array}{l}\text { Expectativa do } \\
\text { mascote do Vasco sair } \\
\text { do fundo do poço. }\end{array}$ & $\begin{array}{l}\text { O mascote do São Paulo } \\
\text { devorado pelos peixes } \\
\text { (simbolizando a derrota } \\
\text { para o Santos). }\end{array}$ \\
\hline & Centro & Ausente & Ausente \\
\hline & Margem & $\begin{array}{l}\text { Assinatura do } \\
\text { chargista e endereço } \\
\text { do blog. }\end{array}$ & $\begin{array}{l}\text { Assinatura do chargista e } \\
\text { endereço do blog. }\end{array}$ \\
\hline Saliência & Máxima & Contraste entre o & Ausente. \\
\hline
\end{tabular}




\begin{tabular}{|l|l|l|l|}
\hline \multirow{2}{*}{ Mínima } & $\begin{array}{l}\text { vermelho da cruz de } \\
\text { Malta e a baixa } \\
\text { saturação do plano de } \\
\text { fundo. }\end{array}$ & Ausente & $\begin{array}{l}\text { Traços de saliência nos } \\
\text { mascotes do Santos e } \\
\text { tamanho do balão de } \\
\text { fala. }\end{array}$ \\
\cline { 2 - 4 } & Fraca & Ausente & Ausente \\
\cline { 2 - 5 } & Forte & $\begin{array}{l}\text { O mascote do Vasco e } \\
\text { plano de fundo (preto) } \\
\text { estão desconectados } \\
\text { devido à presença de } \\
\text { um faixa de cor } \\
\text { branca na diagonal. }\end{array}$ & $\begin{array}{l}\text { A presença de uma linha } \\
\text { divisória na posição } \\
\text { vertical. Lado esquerdo } \\
\text { desconectado do lado } \\
\text { direito. }\end{array}$ \\
\hline
\end{tabular}

Fonte: dados da pesquisa

\section{CONCLUSÃO}

Como vimos no decorrer do artigo, a Semiótica Social possibilita o entendimento das charges de forma sistemática, ampla e coerente como fenômeno da comunicação cultural. Desse modo, não se pode isolar o sistema semiótico visual de sua função social, porque os discursos visuais são realidades socialmente construídas e a sua publicação na mídia são realizações materiais (KRESS, 2000). As formas sociais de organização se engajam com os recursos semióticos próprios que estão à disposição de produtores de textos multimodais. Servimo-nos, portanto, da Teoria da Multimodalidade para aplicar uma terminologia comum, que dentro do discurso do futebol o mesmo significado pode ser expresso em diferentes modos semióticos.

Assim como no texto escrito, os textos visuais apontam para interpretações particulares de experiência e formas de interação social (KRESS e VAN LEEUWEN, 2006). Para ligar as partes do texto em uma composição coesa, o chargista usou diversos recursos semióticos para construir um significado para seu público alvo, isto é, manifestou a metafunção composicional em seu valor de informação, estruturação e saliência. Nas duas charges, o chargista manipulou as zonas espaciais da imagem para estabelecer narrativas em relação aos valores de informação ideal/real e dado/novo. Em relação à estruturação, na primeira charge, as cores desempenharam um papel decisivo na construção da desconexão dos elementos significativos por meio de uma faixa branca na diagonal, separando o mascote do Vasco do plano de fundo preto. Na segunda charge, o autor se apropriou do artifício das 
linhas divisórias para separar quadros narrativos, configurando assim uma estruturação forte. Quanto à saliência, na primeira e segunda charge, o chargista orquestrou as cores e os tamanhos dos elementos para chamar atenção do leitor.

Mais do que um recurso de correção, a GDV é um meio de representação de padrões de experiência. Através dela, verificamos uma projeção visual e humorística da realidade do futebol brasileiro. Ao descrever os significados materializados nas charges, a GDV nos ajuda no desenvolvimento de habilidades de leitura e na construção sentidos de textos multimodais, ou seja, no letramento multimodal. Portanto, saber ler e interpretar textos multimodais é inevitável para se inserir nas diversas práticas sociais do mundo globalizado.

\section{REFERÊNCIAS}

ALMEIDA, D. B. L. Pelos caminhos do Letramento Visual: Por uma proposta multimodal de leitura crítica de imagens. Revista Linguagem em Foco. Fortaleza: EdUECE. Vol. 3, N. 5, p. 43-44, 2011.

AUSTIN, J. L. How to do things with words. Oxford: Oxford University Press, 1962.

BULL, G.; ANSTEY, M. The characteristics of multimodal texts: implications for the teaching of Reading and writing. Evolving pedagogies - Reading and writing in multimodal world. Carlton South, Australia: Curriculum Press, 2010, p. 21 - 46.

CAVALCANTI, M. C. C. Multimodalidade e argumentação na charge. Dissertação (Mestrado Acadêmico). - Universidade Federal de Pernambuco, Centro de Artes e Comunicação, Pós-Graduação em Letras, Recife, 2008.

CHARGES. Disponível em: < www.lancenet.com.br/charges>. Acesso em: 15 nov. 2016.

CUNHA, M. A. F. da; COSTA, M. A.; CEZARIO, M. M. Pressupostos teóricos fundamentais. In: CUNHA, M. A. F. da; OLIVEIRA, M. R. de; MARTELOTTA, M.E. (Org.). Linguística funcional: teoria e prática. São Paulo: Parábola Editorial, 2015, p. 21-45.

GIL, A. C. Como elaborar projetos de pesquisa. 4 ed. São Paulo: Atlas, 2002.

HALLIDAY, M. A. K. An introduction to functional grammar. London: Edward Arnold, 1985.

JEWITT, C. An introduction to multimodality. In: (ed.) The Routledge Handbook of Multimodal Analysis. Londo/New York: Routledge, 2014, p. 14-30.

KNOLL, G. F. Multimodalidade, texto e contexto: categorias úteis à análise da charge. Revista (Con)Textos Linguísticos, Vitória, ES, v. 9, n. 12, p. 57 - 74, 2015. 
KRESS, G. Design and transformation: new theories of meaning. In: COPE, B.; KALANTZIS, M. Multiliteracies: Literacy learning and the design of social futures. London: Routledge, 2000, p. 153-161.

KRESS, G.; VAN LEEUWEN, T. Multimodal Discourse: The modes and media of contemporary communication. London: Arnold, 2001.

2006.

Reading images: the grammar of visual design. London; New York: Routledge,

LAKATOS, E. M.; MARCONI, M. A. Metodologia do trabalho científico: procedimentos básicos, pesquisa bibliográfica, projeto e relatório, publicações e trabalhos científicos. 4 ed. São Paulo: Atlas, 1992.

SAUSSURE, F. Curso de linguística geral. São Paulo: Cultrix, 2004.

\section{OS AUTORES}

Gustavo Ewerson da Rocha Balbino é mestrando em Linguística Aplicada pelo Programa de Pós-Graduação em Linguística Aplicada (PosLA) da Universidade Estadual do Ceará (UECE) e graduado em Letras Português/Literatura pela Universidade Federal do Ceará (UFC). Desde 2014 tem experiência em Educação, atua como professor de Língua Portuguesa, Literatura e Redação no Ensino Médio em escolas particulares e públicas.

E-mail: gustavoerochab@gmail.com

Antonia Dilamar Araújo é doutora em Letras pela Universidade Federal de Santa Catarina (UFSC) e docente do Curso de Letras-Inglês e do Programa de Pós-Graduação em Linguística Aplicada (PosLA) da Universidade Estadual do Ceará (UECE). Desenvolve pesquisas em Semiótica Social, letramento visual, análise de gêneros multimodais e ensino de língua inglesa.

E-mail: dilamar@gmail.com 